\title{
Tense intervention effect in negative emphasis: A case study in Japanese
}

\author{
Yuki Ishihara*
}

\begin{abstract}
This paper investigates two types of predicate emphasis constructions in Japanese: the Affirmative Negative Emphatic Construction and the Emphatic Iterative Construction. It observes that a negative predicate cannot be in past tense in these constructions, and claims that a locality constraint holds between Emphasis and Negation. It suggests that a special property of a past tense form of negation in Japanese can be attributed to a morphological reanalysis.
\end{abstract}

Keywords. emphasis; negation; past tense; Japanese

1. Introduction. In this paper I examine the syntactic properties of two types of predicate emphasis constructions in Japanese and their relation with negation. The two constructions investigated are the Affirmative Negative Emphatic Construction (ANEC) as exemplified in (1) and the Emphatic Iterative Construction (EIC) as in (2A), both of which are used in colloquial Japanese. ${ }^{1}$

(1) Samu-i-no samuku-na-i-no-tte.

cold-NPST-NO cold-NEG-NPST-NO-TTE

'It is/was very cold.'

(2) Q: Nee, Soruto Reeku Shitii-wa samu-i-no?

hey Salt Lake City-TOP cold-NPST-Q

'Hey, is it cold in Salt Lake City?'

A: Un, samu-i samu-i.

yes cold-NPST cold-NPST

'Yes, it IS very cold.'

The ANEC takes the form, X-no X-NEG-no-tte, in which an affirmative predicate followed by no is juxtaposed with its negative counterpart. It is an idiomatic expression that emphasizes the degree of a property denoted by a predicate $\mathrm{X}$ on a scale represented by an affirmative predicate and its negative counterpart at each end. The ANEC in nonpast tense typically describes a present state, but it can also be used to emphasize a state in the past, when a speaker vividly describes a situation in the past as if it were taking place at the time of utterance. ${ }^{2}$ The EIC is a construction in which a tensed verb, adjective, or adjectival noun is repeated twice, and it can emphasize the degree of a property denoted by the predicate. It can also represent a verum focus, when used as an answer to a question, as shown in (2).

Interestingly, it is difficult to use the ANEC in past tense (cf. Martins (1988)), as in (3), or to emphasize a negative predicate in past tense in the EIC (cf. Ishihara (2014, 2015)), as in (4).

\footnotetext{
* I am thankful to the audience at the LSA annual meeting for valuable comments and suggestions. The research reported here was supported in part by JSPS KAKENHI grant number 25370544. Author: Yuki Ishihara, Tokyo Institute of Technology (ishihara@ila.titech.ac.jp).

${ }^{1}$ The abbreviations used in this paper are as follows: $\mathrm{ACC}=$ accusative, GEN=genitive, IMP=imperative, $\mathrm{NEG}=$ negation, $\mathrm{NPST}=$ nonpast, $\mathrm{PST}=$ past, $\mathrm{TOP}=$ topic, $\mathrm{NOM}=$ nominative, and $\mathrm{SFP}=$ sentence final particle.

2 The same holds true with the EIC, when it is used independently.
} 
(3)

$\begin{array}{ll}\text { ?* } \begin{array}{l}\text { Samukat-ta-no } \\ \text { cold-PST-NO }\end{array} & \begin{array}{l}\text { samuku-nakat-ta-no-tte. } \\ \text { cold-NEG-PST-NO-TTE }\end{array}\end{array}$

'It was very cold.'

(4) Q: Nee, Soruto Reeku Shitii-wa samukat-ta-no?

hey Salt Lake City-TOP cold-PST-Q

'Hey, was it cold in Salt Lake City?'

A:?*Uun, samuku-nakat-ta samuku-nakat-ta.

no cold-NEG-PST cold-NEG-PST

'No, it was NOT very cold.'

Why is it that neither the ANEC nor the EIC tolerates a negative predicate in past tense? I address this question in section 3. Before I propose an analysis, however, I briefly go over some of the syntactic properties of the ANEC in section 2, since it has hitherto received little attention in the generative literature. As for the properties and the analysis of the EIC, see Ishihara (2014, 2015). Section 4 concludes the paper.

2. Some properties of the ANEC. The types of predicates that can occur in the ANEC are limited to gradable adjectives, as shown in $(5 \mathrm{a}, \mathrm{b})$, and the contracted form of teiru verbs that denote a gradable state, as in $(5 c, d)$.
a. Atsu-i-no atuku-na-i-no-tte.
hot-NPST-NO hot-NEG-NPST-NO-TTE
'It is/was very hot.'
b. Mushiba-ga ita-i-no itaku-na-i-no-tte. bad.tooth-NOM painful-NPST-NO painful-NEG-NPST-NO-TTE
'The bad tooth hurts/hurt so much.'
c. Tsuukin-densha-ga kon-deru-no kon-de-na-i-no-tte. commute-train-NOM crowd-TEIRU.NPST-NO crowd-TEIRU-NEG-NPST-NO-TTE
'The commuter train is/was very crowded.'
d. Tsukare-teru-no tsukare-te-na-i-no-tte. get.tired-TEIRU.NPST-NO get.tired-TEIRU-NEG-NPST-NO-TTE 'I'm so tired.'

In contrast, nongradable adjectives such as shikaku-i 'square' in (6a), verbs denoting action such as tabe-ru 'eat' in (6b) and adjectival nouns like shizuka-da 'quiet' in (6c) cannot occur in this construction.
a.?* Shikaku-i-no shikakuku-na-i-no-tte. square-NPST-NO square-NEG-NPST-NO-TTE 'It is/was really square.'
b. ??Taroo-ga gohan-o tabe-ru-no tabe-na-i-no-tte.
Taro-NOM meal-ACC eat-NPST-NO eat-NEG-NPST-NO-TTE
'Taro eats/ate so much.'
c. ?*Shizuka-da-no shizukade-na-i-no-tte. quiet-NPST-NO quiet-NEG-NPST-NO-TTE
'It is/was very quiet.'

In the ANEC, the juxtaposition of an affirmative and a negative predicate introduces a scale just as antonym compounds denote a scale, as shown in (7). 
(7)
a. dai-shoo
large-small
'size'
b. choo-tan
long-short
'length'

Since the ANEC is the construction that emphasizes the degree of a state/property denoted by an affirmative predicate, it is natural that nongradable adjectives as in (6a) and verbs not denoting a gradable state as in (6b) should be disallowed in the construction because they are not consistent with a scale of gradability. ${ }^{3}$ As for the ungrammaticality of (6c), it is due to the fact that $d a$, the inflectional ending of adjectival nouns, cannot precede no in this construction.

Now let us consider another construction, the X-no nan-no-tte construction, which also emphasizes the degree of a state/property denoted by a predicate. (8a) shows that gradable adjectives can occur in this construction, and (8b) shows that teiru stative verbs denoting a gradable state can do so as well.
a. Atsu-i-no nan-no-tte.
hot-NPST-NO what-no-tte
'It is/was very hot.'
b. Tsuukin-densha-ga kon-deru-no nan-no-tte. commute-train-NOM crowd-TEIRU.NPST-NO what-NO-TTE 'The commuter train is/was very crowded.'
c. Taroo-ga gohan-o tabe-ru-no nan-no-tte. Taro-NOM meal-ACC eat-NPST-NO what-NO-TTE 'He eats/ate so much.'
d.?* Taroo-ga gakko-ni ik-u-no nan-no-tte. Taro-NOM school-to go-NPST-NO what-NO-TTE intended: 'Taro goes/went to school so much.'

Interestingly, some verbs not allowed in the ANEC can occur in the X-no nan-no-tte construction, as shown in (8c), though there are verbs that are allowed neither in the ANEC nor in the Xno nan-no-tte construction, as in (8d). Whereas a negative predicate used in the ANEC introduces a scale of gradability along with an affirmative predicate, nan 'what' in the X-no nan-no-tte construction allows wider alternatives of comparison for a situation denoted by VP. Thus, in (8c), what is emphasized is not the verb tabe 'eat' itself, but rather is the amount/extent of the activity denoted by the verb, i.e. how much Taro eats. Verbs that do not allow degree modification, e.g. $i k$ 'go' in (8d), cannot occur in the X-no nan-no-tte construction.

I have shown that the X-no nan-no-tte construction is semantically equivalent to the ANEC, though it hosts a wider variety of predicates. Now let us turn to cases where the same string as is used in the ANEC is interpreted in a totally different manner, when it is selected by a predicate that requires juxtaposed propositions.

${ }^{3}$ Verbs that are not accompanied by stative teiru cannot occur in the ANEC. Compare (5d) with (i).

(i) ?? Tsukare-ru-no tsukare-na-i-no-tte. get.tired-NPST-NO get.tired-NEG-NPST-NO-TTE 'I'm so tired.' 

Atsu-i-no
atsuku-na-i-no-tte/to
gochagocha iu-na.
hot-NPST-NO hot-NEG-NPST-NO-TTE /C
grumble say-NEG.IMP

'Don't grumble about the temperature.'

In (9) gochagocha iu 'grumble' selects the sequence X-no X-NEG-no-tte, and in this context, it is interpreted as examples of complaints, and not as emphasis of a state/property denoted by an affirmative predicate. Similarly, when the final -tte is omitted, the sequence is interpreted as disjunctive. $^{4}$

$$
\begin{aligned}
& \text { Atsu-i-no atsuku-na-i-no. } \\
& \text { hot-NPST-NO hot-NEG-NPST-NO } \\
& \text { 'Is it hot or not?' }
\end{aligned}
$$

Since these cases represent juxtaposed propositions, the predicates involved need not be a positive-negative pair.

$$
\begin{array}{llll}
\text { Atsu-i-no } & \text { tsura-i-no-tte } & \text { gochagocha } & \text { iu-na. } \\
\text { hot-NPST-NO } & \text { hard-NPST-NO-TTE } & \text { grumble } & \text { say-NEG.IMP } \\
\text { 'Don't grumble about things such as the temperature and the condition.' }
\end{array}
$$

A piece of evidence that demonstrates that juxtaposed propositions and the ANEC represent different constructions is that the X-no nan-no-tte construction, which can be regarded as a variant of the ANEC, cannot occur as a complement of the verb gochagocha iu 'grumble.'

$$
\begin{array}{lll}
\text { Tabe-ru-no doo-no-tte/*nan-no-tte } & \text { gochagocha } & \text { iu-na. } \\
\text { eat-NPST-NO how-NO-TTE /what-NO-TTE } & \text { grumble } & \text { say-NEG.IMP } \\
\text { 'Don't grumble about whether you are going to eat it or not.' }
\end{array}
$$

What is allowed instead is X-no doo-no-tte, in which doo 'how' represents manner.

The ANEC is a fixed construction with a limited distribution. As a construction of degree emphasis, it is allowed when it occurs by itself, or when it is followed by other emphatic expressions.
a. Atsu-i-no atuku-na-i-no-tte shinu-hodo atsu-i-yo.
hot-NPST-NO hot-NEG-NPST-NO-TTE die-to.the.extent hot-NPST-SFP 'It is so hot that I could die.'
b. Atsu-i-no atuku-na-i-no-tte atsu-i atsu-i. hot-NPST-NO hot-NEG-NPST-NO-TTE hot-NPST hot-NPST 'It is very hot.'

Note that the ANEC and the EIC can co-occur for emphasis, as in (13b).

Turning to the structure of the ANEC, I assume that -tte in the ANEC is a colloquial variant of to, a Report marker, located higher than Force. (cf. Rizzi (1997), Saito (2015)) A marked property of this construction is the fact that a Report marker occurs without a matrix predicate that selects a report complement. As for -no in Japanese, it has three usages: a genitive marker, a pronoun, and a complementizer. Since - $n o$ in the ANEC is neither a case marker nor a pronominal, it should be a nominalizing complementizer. I follow Kuwabara (2013) and regard -no as a Fin(ite) head, independent of Force.

\footnotetext{
${ }^{4}$ When (10) is uttered, both the sequence X-no and the sequence X-NEG-no must be read with a rising intonation and a pause must be inserted between them.
} 
3. The interaction of negation, emphasis, and past tense. As noted in section 1, a negative form in past tense cannot be iterated in the EIC.

$$
\begin{aligned}
& \text { Q: Kinoo-no kaigi nagakat-ta-no? } \\
& \text { yesterday-GEN meeting long-PST-Q } \\
& \text { 'Was yesterday's meeting long?' }
\end{aligned}
$$

A1: Un, nagakat-ta nagakat-ta.

yes long-PST long-PST

'Yes, it WAS very long.'

A2: Uun, nagaku-nakat-ta (?*nagaku-nakat-ta).

no long-NEG-PST long-NEG-PST

'No, it was NOT.'

A3: Uun, nagaku-na-i nagaku-na-i.

no long-NEG-NPST long-NEG-NPST

Lit. 'No, it is NOT.' interpreatable as 'No, it was NOT.'

(14A1-A3) are examples of the EIC with the adjective naga-i 'long., ${ }^{5}$ A question in (14Q) can be answered with a positive EIC, as in (14A1), where polarity is emphasized. Since naga-i is gradable, its degree is also emphasized in (14A1). (cf. Ishihara (2014)) However, when you want to give a negative answer to (14Q), a single negative adjective must be used. The negative adjective cannot be repeated in past tense, as shown in (14A2). Note that the EIC with a nonpast tense negative predicate is allowed as an answer to (14Q), as in (14A3), since the EIC in nonpast tense can be used to emphasize a state in the past, when a speaker vividly describes the situation as if it were taking place "here and now."

Similarly, (15A2) shows the impossibility of the EIC with a negative verb in past tense.

Q: Nee, ano ronbun yon-da?

hey that paper read-PST

'Hey, did you read that paper?'

A1: Un, yon-da yon-da.

yes read- PST read-PST

'Yes, I DID.'

A2: Uun, yoma-nakat-ta $\quad\left(\right.$ ? $^{*}$ yoma-nakat-ta).

no read-NEG-PST

'No, I did NOT.'

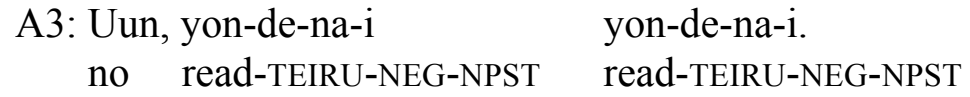

'No, I have NOT.'

A4: Uun, yoma-na-i yoma-na-i.

no read-NEG-NPST read-NEG-NPST

Lit. 'No, I do NOT.' interpretable as 'No, I have NOT.'

While it is OK to use an affirmative verb in past tense in the EIC, as in (15A1), it is difficult to iterate a negative verb in past tense, as in (15A2), in an answer to an affirmative question. In order to give a negative answer to a question in past tense, one can repeat a teiru perfective verb

\footnotetext{
${ }^{5}$ Adjectives in Japanese inflect for tense just like verbs.
} 
form, as in (15A3). A nonpast negative verb form can also be iterated in an answer to (15Q), as in (15A4).

As for the ANEC, it cannot be used in past tense, either.

$$
\begin{aligned}
& \text { a.?* Atsukat-ta-no atsuku-nakat-ta-no-tte. } \\
& \text { hot-PST-NO hot-NEG-PST-NO-TTE } \\
& \text { 'It was very hot.' } \\
& \text { b. Atsukat-ta-no nan-no-tte. } \\
& \text { hot-PST-NO what-NO-TTE } \\
& \text { 'It was very hot.' }
\end{aligned}
$$

Note that the X-no nan-no-tte construction can be used in past tense without any problem, as shown in (16b), so the unacceptability of (16a) cannot be due to the occurrence of an affirmative predicate in past tense, atsukat-ta-no, nor can it be attributed to a reason of semantics.

To sum up the observation thus far, emphasis on negation causes a problem in past tense in both the EIC and ANEC.

\section{*A/V-NEG-PAST-EMP}

How can this restriction be explained?

3.1. NEGATION IN THE EIC IN PAST TENSE. First, let us examine the case of the EIC. Ishihara (2014, 2015) argue that the EIC is derived by head movement of V to a Speech Act head in the C domain, and copy spell-out. Assuming that a functional head hosting an emphasis feature occurs higher than Tense and that Neg(ation) must be in a local relation with the emphasis feature in order to receive an emphatic interpretation, the unacceptability of $(14 \mathrm{~A} 2,15 \mathrm{~A} 2)$ follows; no element with a specified feature, i.e. [+past], can intervene between negation and emphasis.

But why is it that only past tense induces an intervention effect between negation and emphasis? I would like to suggest that a morphological reanalysis may be responsible for it.
a. nakat-ta
NEG-PST
b. at-ta
be-PST
c. nak-at-ta
NEG-be-PST

The negation in past tense takes the form nakat followed by the past tense morpheme $t a$, as shown in (18a). It happens to be the case that the past tense form of a verb of existence, $a-r u$ 'beNPST,' is $a t-t a$, as in (18b). Since the same sequence at occurs both in the verb of existence and in the negative morpheme in past tense, it is plausible for nakat to be reanalyzed as negative nak followed by the verb of existence $a t$, as shown in (18c). ${ }^{6}$

\footnotetext{
${ }^{6}$ A similar possibility of reanalysis was available in Old Japanese.

(i) a. nakari-ki NEG- PST

b. nak-ari-ki NEG-be-PST

c. ari-ki be-PST
} 
If this is the case, we can say that it is difficult to emphasize negation in past tense because while nakat-ta can be reanalyzed as nak-at-ta, in which the affirmative verb of existence, at, is nearer to the emphasis feature than Neg, the emphasis of at results in uninterpretability. Notice that $(14 \mathrm{~A} 3,15 \mathrm{~A} 3,15 \mathrm{~A} 4)$ are fine, because $n a-i$, the nonpast form of negation, has no possibility of a morphological reanalysis.

3.2. THE ANEC IN PAST TENSE. The structure I propose for the ANEC is as follows.

(19) [ReportP [ForceP Op [ConjP [FinP it is x hot no] [Conj' Conj [it is y not hot no]]] Force] tte]

As is shown in section 2, -tte is a Report marker, heading a ReportP, which occurs higher than ForceP in a cartographic theory of phrase structures. The Force head contains an exclamatory head, and its operator searches its domain to determine which FinP to exclaim about. In the search domain of Force, two FinPs, each headed by no with an emphasis feature, are conjoined by a phonetically-null conjunction. Since the first conjunct is located higher in the search domain, being in Spec of ConjP, it is chosen as a target of exclamation. This is the reason why the ANEC is used to emphasize an affirmative predicate, and not the negative one on the scale. ${ }^{7}$

As for the intervention effect, in each FinP, the emphasis feature on no, the Fin head, must be in a local relation with the target of emphasis. When the second conjunct is in past tense, however, negation cannot be in a local relation with the emphatic feature within the second FinP. Here too, nakat-ta can be reanalyzed as nak-at-ta, and at, the verb of existence, intervenes between negation and the emphasis feature. Hence the ANEC in past tense is ill-formed, just as the EIC with a negative predicate in past tense.

4. Concluding remarks. This paper has examined two types of predicate emphatic constructions in Japanese, and has observed the fact that the two constructions share the property of disallowing the emphasis of a negative predicate in past tense. I have claimed that this is due to a locality restriction imposed on the relation between an emphasis feature and negation, and suggested that a morphological reanalysis of a past tense form of negation may be responsible for the intervention effect.

The paper has shown that seemingly idiosyncratic constructions like the ANEC and the EIC are constrained by the same locality constraint on negation and emphasis, which suggests that principles of core grammar are at work even in peripheral domains. This in turn indicates that idiosyncratic constructions in a particular language are worth investigating from the perspective of universal grammar.

The scope of this study is limited to the syntactic properties of the ANEC and EIC. However, emphatic negation in past tense is possible with a phonological stress, in contrast to the situation involving the ANEC and EIC. Emphasis and focus are phenomena that need to be studied across grammatical components. Pragmatic consideration is also necessary to determine emphasis and focus, which again points to the importance of looking at the phenomena from various perspectives. I leave them to future studies.

\footnotetext{
${ }^{7}$ The fact that an affirmative predicate c-commands, and thus precedes, its negative counterpart must be stipulated as an idiosyncratic property of the construction, though it is natural that an unmarked predicate should precede its marked counterpart, as in antonym compounds.
} 


\section{References}

Ishihara, Yuki. 2014. A syntactic analysis of two types of predicate reduplication in Japanese. LSA Annual Meeting Extended Abstracts 2014. http://doi.org/10.3765/exabs.v0i0.2390.

Ishihara, Yuki. 2015. Negation in the predicate reduplication construction in Japanese. Linguistic Research 30. 1-21.

Kuwabara, Kazuki. 2013. Peripheral effects in Japanese questions and the fine structure of CP. Lingua 126. 92-119. https://doi.org/10.1016/j.lingua.2012.12.004.

Martin, Samuel E. 1988. A reference grammar of Japanese. Revised edn. Rutland, VT: Charles E. Turtle Company.

Rizzi, Luigi. 1997. The fine structure of the left periphery. In Liliane Haegeman (ed.), Elements of grammar. 281-337. Dordrecht: Kluwer.

Saito, Mamoru. 2015. Cartography and selection: Case studies in Japanese. In Ur Shlonsky (ed.), Beyond functional sequences. 255-274. Oxford: Oxford University Press. 